\title{
SUSTENTABILIDADE NOS CONTRATOS ADMINISTRATIVOS
}

\author{
Maria Carolina Carvalho de Almendra Freitas ${ }^{1}$ \\ Francisco Cardozo Oliveira ${ }^{2}$ \\ Marcelo de Oliveira Busato ${ }^{3}$
}

\section{RESUMO}

A sustentabilidade passou a ser obrigatória na dinâmica dos contratos públicos e não apenas uma mera ferramenta discricionária de ou conveniência oportunidade da Administração Pública, especialmente a partir do advento da Constituição Federal de 1988 e do recrudescimento da legislação infra-constitucional ambiental, administra-tiva e penal. $\mathrm{O}$ contrato, portanto, deve cumprir sua função social com observância à sua responsabilidade ambiental, econômica e social, sob pena de ilegalidade. A análise da defesa do meio ambiente deve ser uma escolha de política públicas antes mesmo da realização das licitações e contratos, cuja fiscalização e controle se es-tendem não só no momento de execução ou contrato, mas, inclusive, posterior-mente a ele.

Palavras-chave: Sustentabilidade. Contratos Administrativos. Função sócio-ambien-tal e econômica.

\footnotetext{
${ }^{1}$ Graduação em DIREITO pelo CENTRO DE ENSINO UNIFICADO DE TERESINA - CEUT (2003); ESPECIALIZAÇÃO em DIREITO PÚBLICO e em DIREITO PRIVADO pela UNIVERSIDADE FEDERAL DO PIAUÍ - UFPI (2004), MESTRADO em DIREITO INTERNACIONAL E ECONÔMICO pela UNIVERSIDADE CATÓLICA DE BRASÍLIA - UCB (2012); DOUTORANDA em DIREITO POLÍTICO E ECONÔMICO do programa de pós-graduação stricto sensu da UNIVERSIDADE PRESBITERIANA MACKENZIE - UPM. Profissinalmente atuou como advogada no escritório Moisés Reis Advogados Associados (2003-2005); Assessora da presidência no Tribunal Regional do Trabalho da 22 $2^{\mathrm{a}}$ Região (2005-2007); Assessora da presidência do Conselho do Serviço de Apoio a Pequenas e Micro Empresas do Piaú - SEBRAE-PI (20152017); Professora substituta na Universidade Estadual do Piauí - UESPI (2010-2011), no Centro de Ensino Superior do Vale do Parnaíba - CESVALE (2010-2017) e na Faculdade Integral Diferencial - Facid Wyden (2016-2018).

2 Estágio pós-doutoral na Universidade Federal de Santa Catarina (2015), Doutorado em Direito pela Universidade Federal do Paraná (2001), mestrado em Direito pela Universidade Federal do Paraná (1998) graduação em Direito pela Faculdade de Direito de Curitiba (1989), especialização em administração financeira pela Faculdade Católica de Administração e Economia (1984) e graduação em Ciências Contábeis pela Universidade Federal do Paraná (1982). Professor do Programa de Doutorado e Mestrado do Centro Universitário Curitiba.

${ }^{3}$ Mestrando em Direito Empresarial e Cidadania pelo Centro Universitário Curitiba.
} 


\section{INTRODUÇÃO}

É de conhecimento geral e notório que os valores e princípios de proteção e precaução ambiental vem cada vez ganhando cada vez mais força e preocupação na sociedade mundial, de maneira que a sociedade civil vem exigindo providências do Estado e de particulares para realizar a defesa do meio ambiente.

Com efeito, grande parte da população está cotidianamente às voltas com problemas poluição nos rios, córregos e afluentes, esgotamento em geral, contaminações bacteriológicas e intoxicações diversas, cujas doenças, além causar inclusive a morte milhares de pessoas, causam prejuízos incomensuráveis na saúde pública e na própria sociedade.

Portanto, exsurge a necessidade de usar os recursos naturais de maneira racional evitando desperdícios, sem prejuízo de preservar a vida e a qualidade de vida do ser humano.

Assim, avulta uma preocupação gradativamente cada vez mais intensa do Estado e da sociedade civil em geral, em conscientizar a sociedade em geral para proteger os atuais recursos da natureza e prevenir os riscos ambientais e sociais.

Decorrência lógica disso, é a preocupação com os futuros impactos do dano ambiental nos recursos naturais do meio ambiente, de maneira "que os critérios estratégicos da sustentabilidade, no processo de tomada da decisão, requerem maior distanciamento temporal e a capacidade de prospecção de longo prazo, provocando o gestor público a " $a$ exercer, com discernimento, o juízo prospectivo de longo prazo", de maneira que o gestor público deverá ter em mente o horizonte do "Estado Sustentável". 4

Não por acaso, o princípio da sustentabilidade traduz-se em um direito fundamental de índole constitucional previsto nos artigos $3^{\circ}, 225$, e 170-VI da Constituição Federal, possuindo eficácia direta e imediata, impondo "a responsabili-dade do Estado e da sociedade pela concretização solidária do desenvolvimento material e imaterial, socialmente

\footnotetext{
${ }^{4}$ FREITAS, Juarez. Licitações e sustentabilidade: ponderação obrigatória dos custos e benefícios sociais, ambientais e econômicos. Interesse Público. Belo Horizonte: Fórum, a. XIII, n. 70, p. 28, nov./dez. 2011.
} 
inclusivo, durável e equânime, ambientalmente lim-po, inovador e ético no intuito de assegurar, no presente e no futuro, o direito funda-mental ao bem-estar". 5

E, a par de outras ferramentas disponíveis, como a tributação e regula-ção, a sustentabilidade tornou-se princípio orientador das melhores escolhas para o bem-estar das gerações presentes e futuras, sendo certo que o controle dos contratos e licitações públicas poderão realizar estimativas acuradas dos custos diretos e indiretos (externalidades) na busca da melhor escolha das opções oferecidas pelos licitantes, visando não apenas o "menor preço", mas, especial-mente, os "menores impactos e os melhores benefícios legais". (FREITAS, Joarez).

\section{PRINCÍPIOS DA SUSTENTABILIDADE E SUAS REPERCUSSÕES}

A palavra "Sustentabilidade" é relativamente nova, pois surgiu em 1992, quando a Organização das Nações Unidas (ONU) introduziu, oficialmente, a sustentabilidade na agenda global, de maneira que, pela primeira vez, foi criado um programa detalhado direcionado aos governos de todo o mundo, com uma lista de atividades que visavam a proteção e renovação dos recursos ambientais.

O termo até pode ser considerado ser recente, mas a prática é antiga: a sociedade precisa se desenvolver e é necessário haver recursos naturais suficien-tes para isso. O conceito de desenvolvimento sustentável faz parte de uma história que começou no final do século XVII, onde países europeus que faziam uso intenso da madeira para construir os navios, passaram a inventar maneiras de gerenciar esses recursos, resguardando a matériaprima para usos futuros.

Muito embora o assunto estar em pauta há mais de 200 anos, foi somente com a "Agenda 21" em 1992, termo oficial que colocou sustentabilidade entre as prioridades da ONU, que a discussão em torno das ações sustentáveis ganhou novos cenários, chegando finalmente nas salas de reuniões corporativas.

Consoante os princípios da vida sustentável, a doutrina do consagrado ÉDIS MILARÉ, mostra os principais princípios orientadores: 1) respeitar e cuidar da comunidade dos seres vivos; 2) melhorar a qualidade da vida humana; 3) conservar a vitalidade e a

\footnotetext{
${ }^{5}$ FREITAS, Juarez. Revista de Direito Administrativo e Constitucional. Belo Horizonte, ano 13, no 52, p. 35-53, abr/jun 2013.
} 
diversidade do planeta (conservar sistemas de sustentação da vida, a biodiversidade e o uso sustentável dos recursos renováveis); 4) minimizar o esgo-tamento de recursos nãorenováveis; 5) permanecer nos limites da capacidade de suporte do planeta; 6) modificar atitudes e práticas pessoais; 7) permitir que as co-munidades cuidem de seu próprio meio ambiente; 8) gerar uma estrutura nacional para integração de desenvolvimento e conservação; 9) constituir uma aliança glo-bal. ${ }^{6}$

Por outro lado, como premissas, tem-se que, nas lições de JOAREZ DE FREITAS, verbis: a) suas feições são multidimensionais (ética, social, econômi-ca, jurídicopolítica e ambiental; b) vincula ética e juridicamente, inclusive ao assegu-rar a tutela das gerações futuras, pois se trata de princípio constitucional implícito; c) não se coaduna com a crença fetichista e falaciosa no crescimento material como fim em si; d) é diretiva necessariamente associada ao bem-estar duradouro. ${ }^{7}$

Portanto, como princípios e premissas, vinculam e orientam as ações do Estado. Com efeito, "não se trata de simples faculdade, mas de obrigação constitucional e legal realizar licitações e contratações administrativas sustentáveis em todos os Poderes e por todos os poderes.", devendo o gestor público "promover a reconformação da arquitetura das instituições e dos comportamentos: guiado pelo imperativo fundamental da sustentabilidade, o gestor precisa, em todas as relações de administração, promover o bemestar das gerações presentes, sem inviabilizar o bem-estar das gerações futuras, cujos direitos fundamentais são, desde logo, plenamente reconhecidos pelo ordenamento jurídico." 8

E, na medida em que as contratações públicas precisam cumprir políti-cas públicas que busquem o bem-estar das gerações presentes e futuras, a sustentabilidade passa a ser obrigatória, "devendo conter estimativas seguras, confiáveis e inteligíveis dos custos e benefícios sociais, ambientais e econômicos, levando em conta a preferência simultânea por menores impactos negativos e maiores benefícios globais". 9

\footnotetext{
${ }^{6}$ MILARÉ, Édis. Direito do ambiente: doutrina, jurisprudência, glossário. $4^{\text {a }}$ ed. São Paulo: Revista dos Tribunais, 2005, doutrina, jurisprudência, glossário, p. 65-68

${ }^{7}$ FREITAS, Juarez. Sustentabilidade: direito ao futuro. Belo Horizonte: Fórum, 2011, p. 18-19.

${ }^{8}$ FREITAS, Juarez. Licitações e sustentabilidade: ponderação obrigatória dos custos e benefícios sociais, ambientais e econômicos. Interesse Público. Belo Horizonte: Fórum, a. XIII, n. 70, p. 19; 22, nov./dez. 2011.

9 FREITAS, Juarez. Licitações e sustentabilidade: ponderação obrigatória dos custos e benefícios sociais, ambientais e econômicos. Interesse Público. Belo Horizonte: Fórum, a. XIII, n. 70, p. 35 nov./dez. 2011.
} 
Aliás, as exigências de sustentabilidade obrigam inclusive a formatação de instrumentos convocatórios das licitações, conforme a mens legis do artigo 225 da e o artigo $3^{\circ}$ da Lei Federal $n^{\circ}$ 8.666, com a redação atribuída pela Lei Federal $n^{\circ} 12.349$, de maneira que vinculam os procedimentos licitatórios como um todo.

Confirmando a importância do desenvolvimento sustentável, a Excelsa Corte já se pronunciou, verbis:

\begin{abstract}
"O princípio do desenvolvimento sustentável, além de impregnado de caráter eminentemente constitucional, encontra suporte legitimador em compromissos internacionais assumidos pelo Estado brasileiro e representa fator de obtenção do justo equilíbrio entre as exigências da economia e as da ecologia, subordinada, no entanto, a invocação desse postulado, quando ocorrente situação de conflito em-tre valores constitucionais relevantes, a uma condição inafastável, cuja observân-cia não comprometa nem esvazie o conteúdo essencial de um dos mais signifi-cativos direitos fundamentais: $\mathrm{O}$ direito à preservação do meio ambiente, que tra-duz bem de uso comum da generalidade das pessoas, a ser resguardado em favor das presentes e futuras gerações e especialmente protegidos qualificam-se, por efeito da cláusula inscrita no art. $225, \S 1^{\circ}$, III, da Constituição, como matérias sujeitas ao princípio da reserva legal". ${ }^{10}$
\end{abstract}

No mesmo sentido a doutrina vem sustentando que a sustentabilidade não é princípio meramente abstrato ou de observância adiável, pois "vincula plena-mente e se mostra inconciliável com o vicioso descumprimento da função sócio-ambiental dos bens e serviços", porquanto é que dela decorre a obrigação de reavaliar políticas públicas, cobrar a alocação equitativa de recursos públicos poupados e direcionados à universalização do bemestar físico psíquico e espiritual, pois, "O próprio Estado Constitucional só faz sentido a serviço dos fins éticos rela-cionados à sustentabilidade do bem-estar". ${ }^{11}$

\title{
3. CONTRATAÇÕES E LICITAÇÕES SUSTENTÁVEIS: EXIGÊNCIA OBRIGATÓ- RIA
}

Diante das exigências decorrentes do princípio do direito fundamental da sustentabilidade, as contratações públicas devem observar a proteção do meio am-biente sadio e equilibrado como elemento do interesse público primário, com o nítido interesse de buscar

\footnotetext{
${ }^{10}$ ADI-MC n ${ }^{\circ}$ 3.540-DF, rel. Min. Celso de Mello, Pleno do STF, DJU de 03.02.2006.

${ }^{11}$ FREITAS, Juarez. Sustentabilidade: direito ao futuro, op. cit., 2011, p. 39; 59; 64-65 e 117.
} 
o uso de tecnologias limpas para a aquisição de produtos "ver-des", investir em energias renováveis, em processos de reciclagem material e ima-terial, buscar alternativas menos poluentes nas matrizes de transportes entre outras práticas sustentáveis.

Coroando os princípios da obrigatoriedade da proteção ao meio am-biente bem como do desenvolvimento sustentável, a lei de licitações, no artigo $3^{\circ}$, é clara a respeito:

\begin{abstract}
“Art. 3o A licitação destina-se a garantir a observância do princípio constitucional da isonomia, a seleção da proposta mais vantajosa para a administração e a promoção do desenvolvimento nacional sustentável e será processada e julgada em estrita conformidade com os princípios básicos da legalidade, da impessoali-dade, da moralidade, da igualdade, da publicidade, da probidade administrativa, da vinculação ao instrumento convocatório, do julgamento objetivo e dos que lhes são correlatos. (Redação dada pela Lei n ${ }^{\circ} 12.349$, de 2010)" (grifo nosso).
\end{abstract}

A respeito do tema, didática é a lição de Juarez Freitas:

\begin{abstract}
"A obrigatoriedade de licitações sustentáveis, em todas as esferas federativas, isto é, cumpre partir para a implementação imediata das licitações sustentáveis, com a adoção de critérios objetivos, impessoais e fundamentados de sustentabili-dade para avaliar e classificar as propostas, em todos os certames, com novo con-ceito de proposta vantajosa. A obrigatoriedade decorre da aplicação direta do prin-cípio em tela, tese facilitada após sua recente explicitação, que alterou o art. $3^{\circ}$ da Lei de Licitações" (destaque nosso). ${ }^{12}$
\end{abstract}

Desta forma, em atenção ao compromisso constitucional expresso, e tam-bém explicitado no Estatuto das Licitações, tem o Estado a responsabilidade de ini-bir ou vedar contratações deletérias do meio ambiente, concretizando os princípios da sustentabilidade e do desenvolvimento sustentável.

Diante disso, não se revela razoável omissões ou falhas do Estado em proteger direitos fundamentais como proteção ao meio ambiente. E, para que se evite eventuais "falha na guarda preventiva da sustentabilidade" pela Administração, impõe-se, agora, que os editais adotem critérios de concretização direta do princípio da sustentabilidade, com todas os efeitos e consequências decorrentes, especial-mente no que tange a qualificação técnica dos contratados.

Nesse ponto, importante e esclarecedora é a doutrina da professora RAQUEL CARVALHO:

${ }^{12}$ FREITAS, Juarez. Sustentabilidade: direito ao futuro, op. cit., p. 90-91. 


\begin{abstract}
"Nesse sentido, o direito fundamental à proteção ambiental e o princípio da sustentabilidade consistem em limite à discricionariedade administrativa presente quando da elaboração de atos normativos como instruções e portarias regulamentadoras de licitações, bem como dos editais e das cartas-convite. A exigência, para que sejam firmados contratos administrativos, de produtos que possuam maior dura-bilidade e que causem menor impacto ambiental pode resultar em mudanças signi-ficativas no mercado, tendo em vista o interesse das empresas em auferir lucro em negócios firmados pelo Estado. O poder de compra estatal torna-se, assim, em eficiente instrumento de concreção do desenvolvimento sustentável."13
\end{abstract}

A propósito disso, acerca da importância de o Poder Público ser agente protagonista de políticas públicas ambientais, vale trazer os ensinamentos da doutrina de ANDRÉ LUIS VIEIRA:

"Melhor dizendo, é o Poder Público o principal ator a figurar como agente indutor de políticas públicas ambientais, aí incluídas aquelas que tratam dos critérios de sustentabilidade para as compras governamentais.

$(\ldots)$

O poder de compra governamental funciona como um relevante instrumento de promoção do desenvolvimento sustentável. Valendo-se deste poder, estimado entre $10 \%$ do PIB, o Estado brasileiro deve induzir o comportamento do setor pro-dutivo, orientando-o em favor da incorporação de critérios de sustentabilidade na elaboração de bens e serviços, criando as condicionantes favoráveis para o estabelecimento definitivo de um mercado de produtos sustentáveis. A concretiza-ção de tal hipótese, antes de tudo, conferiria alto grau de efetividade à tutela ambiental". ${ }^{14}$

Também, no mesmo sentido - demonstrando o poder-dever do Poder Público de influenciar o setor produtivo e a matriz produtiva -, precisa é a lição de JUAREZ FREITAS:

"Outro ponto, com o seu gigantesco poder de contratação (mais de dez por cento do PIB), cumpre ao Poder Público influenciar a matriz produtiva, num foco de convergência para que os fornecedores, públicos e privados, comecem a se tornar vigilantes quanto à sustentabilidade do ciclo de vida dos produtos - desde a obtenção de matérias-primas e insumos, passando pelo processo produtivo e consumo até a disposição final. Eis uma providencial alteração de compreensões prévias, que ostenta o condão de reorientar, na íntegra, as contratações em geral." 15

E, não se pode deixar de mencionar a obrigatoriedade de se realizar os estudos e os relatórios de estudos de impacto ambiental nos projetos básicos e executivos de obras e serviços previstos no artigo 12 da Lei de Licitações (RIMA e EIA-RIMA), ilustrando mais

\footnotetext{
${ }^{13}$ CARVALHO, Raquel (http://raquelcarvalho.com.br/2018/05/24/sustentabilidade-licitacao-e-contratosadministrativos-parte-2/). Acessado em 07.08.2019.

${ }^{14}$ VIEIRA, André Luís. Contratações públicas sustentáveis, op. cit., p. 33 e 39.
} 
uma vez a obrigatoriedade de as licitações e contratações públicas e observarem as normas ambientais.

Esclarecedora e oportuna também, nesse aspecto, é a lição e doutrina de ANDRE LUÍS VIEIRA, demonstrando a indispensabilidade de se realizar os estudos de impacto ambiental e relatórios de impacto ambiental na fase inicial e interna da licitação:

\begin{abstract}
"Não há dúvida que o artigo 12 da Lei de Licitações já determinava que fosse comsiderado nos projetos básicos e executivos de obras e serviços, o impacto ambien-tal, assim como a funcionalidade e adequação ao interesse público. Estudos de Impacto Ambiental e Relatórios de Impacto Ambiental afiguram-se como docu-mentos indispensáveis ainda na fase interna da licitação. Também já se indica que procedimentos licitatórios com julgamento pela melhor técnica ou técnica e preço contemplem, de forma objetiva, critérios ambientais como fator de pontuação das propostas, levando-as em conta na definição da proposta que melhor atende ao interesse público. No entanto, a sustentabilidade inserida pela Lei $\mathrm{n}^{\circ} 12.349$, de 15.12.2010 inova e integra novas medidas como possíveis. Ao especificar os objetos nos termos de referência, projetos básicos e projetos executivos, podem cons-tar quesitos como, por exemplo, baixo consumo e racionalização do uso de água ou de energia elétrica, visando contribuir para a efetiva proteção ambiental. A intenção é privilegiar tecnologias limpas, redução de desperdício de materiais e combustíveis, processos produtivos ambientalmente responsáveis e com respeito a direitos trabalhistas e previdenciários, uso de metodologia de aferição da relação custo durabilidade, da disposição final de resíduos e da difusão de boas práticas de modelo de gestão contratual. Para tanto, é preciso identificar quais são os critérios e regras de sustentabilidade aplicáveis a cada produto, promover ativi-dades de educação ambiental com conscientização dos servidores quanto às boas práticas administrativas e ambientais, ao que se acresce o esclarecimento do público (interno e externo) sobre o papel do Estado na questão ambiental, inclusi-ve servindo de exemplo de eficiência de gestão. ${ }^{16}$
\end{abstract}

Assim, como se vê, as contratações públicas, decorrentes de licitações, em todos as suas fases, pressupõem, inexoravelmente, o cumprimento e observân-cia das exigências legais decorrentes do princípio da sustentabilidade buscando a proteção do meio ambiente sadio e equilibrado como elemento do interesse público primário.

\title{
4. FUNDAMENTOS NORMATIVOS DA LICITAÇÃO SUSTENTÁVEL
}

Os princípios da sustentabilidade e do desenvolvimento sustentável, não estão apenas previstos na Constituição Federal (CF, artigo 225 e 170, VI), mas também constituem

${ }^{15}$ FREITAS, Juarez. Licitações e sustentabilidade: ponderação obrigatória dos custos e benefícios sociais, ambientais e econômicos. Interesse Público, op. cit., p. 19, itálico no original.

${ }^{16}$ VIEIRA, André Luís. Contratações públicas sustentáveis, op. cit., p. 37-39. 
em direitos e garantias constitucionais com eficácia imediata, que possuem as características da inalienabilidade, imprescritibilidade e irrenun-ciabilidade.

Sucede que, para alcançar tão importante missão (mens legislatoris), imprescindível que haja tratamento jurídico próprio e adequado da matéria, bem como ferramentas técnicas que instrumentalizem a sustentabilidade e o desenvolvi-mento sustentável como direito inerente à cidadania. Não por acaso, vários diplomas legais já traziam parâmetros de sustentabilidade como é do artigo $3^{\circ}$ da Lei de Licitações (Lei 8.666 de 1993), a lei da Política Nacional de Meio Ambiente veiculada pela Lei Federal $n^{\circ}$ 6.938/81 (especialmente com as redações dos artigos $4^{\circ}, \mathrm{I}, \mathrm{IV}, \mathrm{V}$ e $\mathrm{VI}$, o parágrafo único do artigo $5^{\circ} \mathrm{e}$ o artigo 10, com a redação da Lei Complementar nº 140/2011).

É de se lembrar também o artigo 12 da Lei de Licitações (Lei Federal n 8.666/93) que torna obrigatória, nos casos de contratação de obras e serviços de engenharia, considerar e concretizar paradigmas de sustentabilidade nos projetos básico e executivo, atentando para impacto ambiental, possibilidade de emprego de materiais e tecnologia existentes no local da execução e operação, adoção de normas de segurança do trabalho, dentre outros (CARVALHO, Raquel).

Também, podemos citar, entre outros, os seguintes diplomas legais: (a) o artigo $4^{\circ}$, VII da Lei de Parcerias Público-Privadas (Lei Federal no 11.079/04) que trouxe como diretriz vinculante a "sustentabilidade financeira e vantagens socioeconômicas dos projetos de parceria; (b) a Lei Federal no 12.187/09 que trata sobre a política nacional sobre mudança do clima onde menciona expressamente o desenvolvimento sustentável e o princípio da prevenção (artigo $3^{\circ}$, “caput"), fixando compatibilização entre desenvolvimento econômicosocial com proteção do sistema climático (artigo $4^{\circ}$, I); (c) a Lei Federal $\mathrm{n}^{\circ}$ 12.305, de 02.08.2010, que instituiu a política nacional de resíduos sólidos, trazendo impôs como objetivos a prioridade para aquisição de produtos reciclados e recicláveis, bem como de bens, serviços e obras que considerem critérios compatíveis com padrões de consumo social e ambientalmente sustentáveis, fixando, outrossim, como objetivo o estímulo à imple-mentação da avaliação do ciclo de vida do produto, o incentivo ao desenvolvimento de sistemas de gestão ambiental e empresarial voltados para a melhoria dos processos produtivos e ao reaproveitamento dos resíduos sólidos, incluídos a recuperação e o aproveitamento energético, bem como o estímulo à rotulagem ambiental e ao consumo sustentável (artigo $7^{\circ}$, XI, XII, XIII, XIV e XV). (CARVALHO, Raquel). 
No que tange às leis de Mudança do Clima (Lei 12.187 de 2009), bem como a Lei de Resíduos Sólidos, pontua a doutrina de Maria Augusta Soares de Oliveira Ferreira, verbis:

\begin{abstract}
"A Lei de Mudança do Clima, ao estabelecer a preferência nas licitações por produtos que propiciem uma maior economia de energia, água e outros recursos naturais, bem como a favor da redução da emissão de resíduos, vem a ser fortalecida pela nova lei de resíduos sólidos. Comparando-se os termos do art. $6^{\circ}$, XII, da lei de mudança do clima e o art. $7^{\circ}$, XI, 'a' e 'b', da lei de resíduos sólidos, percebe-se claramente a complementariedade entre os dois, pois a reciclagem e o consumo social e ambientalmente sustentáveis (Lei de Resíduos Sólidos) são dois pilares primordiais para o enfrentamento das mudanças climáticas e exemplos fundamentais de medidas para uma maior economia de energia, água e outros recursos naturais, bem como para a redução da emissão de resíduos, conforme determinado pela Lei de Mudança do Clima." $" 17$
\end{abstract}

\begin{abstract}
“Além disso, os artigos 30, 31 e 32 da Lei Federal n 12.305/10 dispõem acerca da responsabilidade compartilhada; trazem exigências para produtos a serem licita-dos pela Administração que não pode estimular o descumprimento da Lei de Resí-duos sólidos - política que instituiu - ao aceitar que concorram em licitações pro-dutos cujos responsáveis, fabricantes, importadores, distribuidores e comercian-tes descumpram a lei ou mesmo o plano de gerenciamento obrigatório (artigo 27). "Significa dizer que, caso esteja disponível no mercado, a preços razoáveis (lembrando os princípios da proporcionalidade e da razoabilidade adiante analisados), produtos que sejam, por exemplo, fabricados a partir de material reciclado, a Administração deverá, nos termos da lei (art. $7^{\circ}$, XI, 'a'), dar preferência a esses produtos." Frise-se, cumulativamente, a previsão de responsabilidade compartilhada e redução de consumo, sendo certo que a Administração terá que dar preferência a produtos com embalagens menores (art. $7^{\circ}$, XI, v e artigo 31). Outros exemplos de sustentabilidade oriundos da lei são a exigência nas licitações de que pessoas jurídicas a serem contratadas cumpram as obrigações da logística rever-sa (art. 33), do cadastramento em razão de operarem com resíduos perigosos (art. 38) e de não incorrerem nas proibições do artigo $47 .^{18}$
\end{abstract}

De se lembrar, também, a importância das Leis 12.187/09 (Lei da Política Nacional sobre Mudança do Clima) bem como da lei 12.305/10 (Lei da Política Nacional e Resíduos Sólidos) que introduziram previsão legal expressa de inclusão de critérios preferenciais para contratações de objetos coerentes com a preservação do meio ambiente. Em seu artigo $6^{\circ}$, XII, a Lei 12.187/09 determinou o "estabelecimento de critérios de preferências nas licitações e concorrências públicas (...) para as propostas que propiciem maior economia de energia, água e outros recursos naturais e redução da emissão de gases de efeito estufa e de resíduos", Por outro lado, o artigo 7, XI, “a" e "b" da Lei Federal n 12.305/10, determinou a prioridade nas aquisições e contratações governamentais para: a) produtos reciclados e

17 FERREIRA, Maria Augusta Soares de Oliveira. Apontamentos sobre a gestão socioambiental na administração pública brasileira in Sustentabilidade na Administração Pública: Valores e práticas de gestão socioambiental. Coordenadores: BLIACHERIS, Marcos Weiss. FERREIRA, Maria Augusta Soares de Oliveira. Belo Horizonte: Fórum, 2012, p. 126.

18 FERREIRA, Maria Augusta Soares de Oliveira. Apontamentos sobre a gestão socioambiental na administração pública brasileira in Sustentabilidade na Administração Pública: Valores e práticas de gestão socioambiental, ob cit. 127-128. 
recicláveis; b) bens, serviços e obras que considerem critérios compatí-veis com padrões de consumo social e ambientalmente sustentáveis (CARVALHO, Raquel).

Acrescente-se à legislação federal, inúmeros diplomas de leis estaduais e municipais que dispõe sobre a Política Estadual de Resíduos Sólidos consagrando, em síntese, os seguintes aspectos relevantes:

a) a coleta seletiva: recolhimento diferenciado de resíduos sólidos previamente selecionados nas fontes geradoras, com o intuito de encaminhá-los para reutilização, reaproveitamento, reciclagem, compostagem, tratamento ou destinação final ade-quada;

b) destinação final ambientalmente adequada dos resíduos: encaminhamento dos resíduos sólidos para que sejam submetidos ao processo adequado, seja ele a reutilização, o reaproveitamento, a reciclagem, a compostagem, a geração de ener-gia, o tratamento ou a disposição final, de acordo com a natureza e as caracte-rísticas dos resíduos e de forma compatível com a saúde pública e a proteção do meio ambiente;

c) disposição final ambientalmente adequada dos rejeitos: disposição dos resíduos sólidos em local adequado, de acordo com critérios técnicos aprovados no processo de licenciamento ambiental pelo órgão competente;

d) gestão integrada dos resíduos sólidos: conjunto articulado de ações políticas, normativas, operacionais, financeiras, de educação ambiental e de planejamento desenvolvidas e aplicadas aos processos de geração, segregação, coleta, manu-seio, acondicionamento, transporte, armazenamento, tratamento e destinação final dos resíduos sólidos;

e) logística reversa dos resíduos sólidos: conjunto de ações e procedimentos desti-nados a facilitar a coleta e a restituição dos resíduos sólidos aos geradores, para que sejam tratados ou reaproveitados em seu próprio ciclo produtivo ou no ciclo produtivo de outros produtos;

f) manejo integrado de resíduos sólidos: por meio da operacionalização dos resíduos sólidos gerados pelas instituições privadas e daqueles de responsabilidade dos serviços públicos, compreendendo as etapas de redução, segregação, coleta, mani-pulação, acondicionamento, transporte, armazenamento, transbordo, triagem, trata-mento, comercialização e destinação final adequada dos resíduos, observados princípios e diretrizes estabelecidas no Plano de Gestão Integrada de Resíduos Sólidos; 
g) reaproveitamento dos resíduos sólidos: por meio de processo de utilização dos resíduos sólidos para outras finalidades, sem sua transformação biológica, física ou química;

h) reutilização dos resíduos sólidos: por meio de processo de utilização dos resíduos sólidos para a mesma finalidade, sem sua transformação biológica, física ou química.

Assim, cumpre consignar que, para além da previsão estatuída no artigo $3^{\circ}$ da Lei Federal $\mathrm{n}^{\circ}$ 8.666, vários outros diplomas em vigor, nas esferas estaduais, distrital e municipais, também servem como fundamento do arcabouço legislativo apto a cumprir a missão da sustentabilidade e também do desenvolvimento sus-tentável nos entes federados do Estado brasileiro, incorporando mencionadas exigências de sustentabilidade e sua principiologia em todos os contratos adminis-trativos. (CARVALHO, Raquel).

\section{CONCLUSÃO}

Embora a busca pela proteção do meio ambiente seja antiga, o termo "sustentabilidade" surgiu no ano de 1992, no momento em que a Organização das Nações Unidas (ONU) introduziu, oficialmente, por meio da "agenda 21" da "RIO 92", a principiologia da "sustentabilidade" na agenda global, de maneira que, pela primeira vez, foi criado um programa detalhado direcionado aos governos de todo o mundo, com uma lista de atividades que visavam a proteção e renovação dos recursos ambientais.

Em linhas gerais, o princípio da sustentabilidade busca o uso eficaz e racional do meio ambiente por meio do "desenvolvimento sustentável", pois, se a sociedade precisa se desenvolver, é necessário haver recursos naturais suficientes para isso.

Diante da importância constitucional do tema, sustentabilidade constitui não só um direito e garantia fundamental, como mandamento da Constituição Fede-ral (CF, art. 225, e art. 170-VI) com efeitos diretos e imediatos sobre todos os entes públicos e particulares (CF, art. $5^{\circ}$, parágrafo único), cuja normativa se estende para vários diplomas legais da legislação infra-constitucional (Lei de Licitações, Lei da Política Nacional do Meio Ambiente, Lei da Mudança Climática, Lei dos Resíduos Sólidos, Lei das Águas, Lei da Mobilidade Urbana, entre outros).

No que tange às contratações públicas por meio de licitações, a Lei 8.666/1993 
prevê expressamente, em seu artigo $3^{\circ}$, a "promoção do desenvol-vimento nacional sustentável", tornando obrigatória o cumprimento das exigências de sustentabilidade nas licitações públicas, sob pena de ilegalidade e eventual nulidade da licitação ou contratação.

Portanto, na análise das licitações e contratações públicas, os gestores públicos e a Administração Pública devem observar referidos princípios decorrentes da sustentabilidade, observando todos os benefícios diretos e indiretos (sociais, am-bientais e econômicos) do contrato, bem como o exame dinâmico e intertemporal das propostas, e se a contratação é realmente necessária.

Não bastasse isso, na escolha da melhor proposta, os gestores públicos não só podem, como devem, escolher não apenas a proposta "de menor preço", mas, sobretudo a que concilie a "sustentalidade com o melhor preço", na medida em que as propostas com preços mais baixos, não raramente, deixam de atender os critérios da sustentabilidade e da legislação ambiental.

Com isso, evitar-se-á inúmeros riscos e danos ambientais que atentem em desfavor dos consagrados princípios administrativos constitucionais da legali-dade, impessoalidade, moralidade, publicidade e eficiência previstos no art. 40 e seguintes da Constituição Federal.

\section{REFERENCIAL}

ADI-MC no 3.540-DF, rel. Min. Celso de Mello, Pleno do STF, DJU de 03.02.2006.

CHEVALLIER, Jacques. O Estado pós-moderno. Tradução de Marçal Justen Filho, Belo Horizonte: Fórum, 2009.

CHEVALLIER, Jacques. O Estado pós-moderno.

EUSTÁQUIO, Leandro. Direito ambiental para concursos. Jurisprudência do STF, STJ e exercícios selecionados. Rio de Janeiro: Lumen Juris, 2008.

FERREIRA, Daniel; PELLEGRINELLO, Ana Paula. Grandes obras, grandes impactos e a promoção (controlada e controlável) do desenvolvimento nacional sustentável. Revista Juridica, [S.1.], v. 1, n. 34, p. 376-398, fev. 2014. ISSN 2316-753X. Disponível em: <http://revista.unicuritiba.edu.br/index.php/RevJur/article/view/799/612>. Acesso em: 21 abr. 2020. doi:http://dx.doi.org/10.21902/revistajur.2316-753X.v1i34.799. 
FREITAS, Juarez. Licitações e sustentabilidade: ponderação obrigatória dos custos e benefícios sociais, ambientais e econômicos. Interesse Público. Belo Horizonte: Fórum, a. XIII, n. 70, nov./dez. 2011.

FREITAS, Juarez. Sustentabilidade: direito ao futuro. Belo Horizonte: Fórum, 2011.

FREITAS, Juarez. Licitações e sustentabilidade: ponderação obrigatória dos custos e benefícios sociais, ambientais e econômicos. Interesse Público. Belo Horizonte: Fórum, a. XIII, n. 70, nov/dez 2011.

GOMES, Carla Amado. Direito administrativo do ambiente. In: Tratado de Direito Administrativo Especial: Coord. OTERO, Paulo. GONÇALVES, Paulo. Coimbra: Almedina, 2009.

MILARÉ, Édis. Direito do ambiente: doutrina, jurisprudência, glossário. $4^{\mathrm{a}}$ ed. São Paulo: Revista dos Tribunais, 2005.

VALLE, Vanice Regina Lírio. Sustentabilidade das escolhas públicas: dignidade da pessoa traduzida pelo planejamento público. A\&C Revista de Direito Administrativo \& constitucional. Belo Horizonte: Fórum, a. 11, n. 45, jul/set 2011.

VIEIRA, André Luís. Contratações públicas sustentáveis. Fórum de Contratação e Gestão Pública. Belo Horizonte: Fórum, a.9, n. 100, abr.-2010. 